тологии / под ред. А. И. Воробьева, издание третье в 3-х т. Т. 3., М.: Ньюдиамед, 2005. С. 45 - 73.

3.Гемофилия. Протокол ведения больных. М. 2006. 120 c.

4.Мамаев А.Н. Коагулопатии. М.: ГЭОТАР-Медиа. 2012. $260 \mathrm{c}$.

5.Зозуля Н.И., Кумскова М.А. Протокол диагностики и лечения гемофилии // в кн. Алгоритмы диагностики и лечения заболеваний системы крови. Под ред. В.Г. Савченко. 2018. Т.1. С. 333 358.

6.Colvin BT, Astermark J, Фischer K, Gringeri A, Lassila R, Schramm W, Thomas A, Ingerslev J; Inter Disciplinary Working Group. European principles of haemophilia care. Haemophilia 2008;14(2):361-74.

7.De Moerloose $P$, Fischer $K$, Lambert $T$ et al. Recommendations for assessment, monitoring and follow-up of patients with haemophilia. Haemophilia 2012; 18: 319-25.

8.Wojciechowski V.V., Calina D., Tsarouhas K., et al. A guide to acquired vitamin $k$ coagulophathy diagnosis and treatment: the russian perspective DARU Journal of Pharmaceutical Sciences. 2017. T. 25. № 1. C. 10.

Статья поступила в редакцию 25.01.2019

\section{Координаты для связи}

Есенина Татьяна Владимировна, заведующая гематологическим отделением ГАУЗ АО «Амурская областная клиническая больница». E-mail: esenina-09@mail.ru

Филатова Екатерина Александровна, к. М. н., врач гематологического отделения ГАУЗ АО «Амурская областная клиническая больница». E-mail: Ekaterina.gladun.86@mail.ru

Мишкурова Кристина Михайловна, врач гематологического отделения ГАУЗ АО «Амурская областная клиническая больница».

Федорова Наталья Анатольевна, врач гематологического отделения ГАУЗ АО «Амурская областная клиническая больница».

Почтовый адрес ГАУЗ АО «Амурская областная клиническая больница»: 675027, Амурская область, г. Благовещенск, ул. Воронкова 26.
УдК 591.494(678.048):616-001.18/.19

В.А. Доровских, Н.В. Симонова,

Р.А. Анохина, М.А. Штарберг, Е.Ю. Лемеш

ФГБОУ ВО Амурская ГМА Минздрава

России

г. Благовещенск

ХОЛОДОВАЯ АДАПТАЦИЯ

ТЕПЛОКРОВНОГО ОРГАНИЗМА И ЕЕ КОРРЕКЦИЯ ЦИТОФЛАВИНОМ

\section{Введение}

При адаптации организма к холоду наблюдается диспропорция в гормональном и энергетическом статусе анаболических процессов, возникает дефицит биоэнергетических ресурсов и гипоксия тканей $[1,5]$ в основе которого лежит несоответствие между потребностью тканей в кислороде и его доставкой, связанное прежде всего с нарушением окисления в результате затруднения транспорта электронов в дыхательной цепи митохондрий, что приводит к повреждению мембран лизосом с выходом аутолитических энзимов в межклеточное пространство $[9,14,16]$. Сложный механизм развития гипоксии в организме, многокомпонентная система биохимических и метаболических процессов, возникающих при различной патологии, объясняет трудности в назначении препаратов, выполняющих задачи коррекции функций дыхательной цепи и других метаболических процессов, поставляющих энергетические субстраты [7]. Перспективным с этих позиций представляется использование препаратов, содержащих янтарную кислоту, являющуюся одним из метаболитов цикла Кребса, экзогенное поступление которой восстанавливает процессы энергообмена $[4,6,12]$.

Янтарная кислота, представленная в организме в виде аниона (сукцината), содержится в препарате цитофлавин, дезинтоксикационное, антигипоксическое и антиоксидантное действие которого доказано в доклинических и клинических исследованиях $[8,12]$.

Цель работы - изучить эффективность цитофлавина при адаптации теплокровного организма к холоду.

\section{Методы исследования}

Данный эксперимент проводили на белых беспородных крысах-самцах массой 150-200 г в течение 21 дня. Протокол экспериментальной части исследования на этапах содержания животных, моделирования патологических процессов и выведения их из опыта соответствовал принципам биологической этики, изложенным в Международных рекомендациях по проведению медико-биологических исследований с использованием животных (1985), Европейской конвенции о защите позвоночных животных, используемых для экспериментов или в иных научных целях (Страсбург, 1986), Приказе МЗ СССР №755 от 12.08.1977 «О мерах по дальнейшему 
совершенствованию организационных форм работы с использованием экспериментальных животных», приказе МЗ РФ №267 от 19.06.2003 «Об утверждении правил лабораторной практики». При завершении научных исследований выведение животных из опыта проводили путем декапитации с соблюдением требований гуманности согласно приложению № 4 к Правилам проведения работ с использованием экспериментальных животных (приложение к приказу M3 СССР № 755 от 12.08.1977 «О порядке проведения эвтаназии (умерщвления животного)». Исследование одобрено Этическим комитетом ФГБОУ ВО Амурская ГМА Минздрава России.

Охлаждение животных осуществляли ежедневно в условиях климатокамеры Fentron (Германия), создавая температурный режим $-15^{\circ} \mathrm{C}$ с соблюдением адекватных условий влажности и вентиляции. Животные были разделены на 3 группы, в каждой по 30 животных: 1 группа интактная, животные содержались в стандартных условиях вивария; 2 группа - контрольная, животные подвергались воздействию холода в течение 3 часов ежедневно в течение 21 дня на фоне ежедневного внутрибрюшинного введения животным непосредственно перед охлаждением эквиобъемного вводимому препарату цитофлавин (3 группа) количества физраствора; 3 группа - подопытная, животным непосредственно перед охлаждением (время экспозиции - 3 часа) ежедневно внутрибрюшинно вводили цитофлавин в дозе 100 мг/кг. Цитофлавин является сбалансированным комплексом из двух метаболитов (янтарная кислота, рибоксин) и двух коферментов витаминов (рибофлавин мононуклеотид - витамин В2, никотинамид - витамин РP). Забой путем декапитации проводили на 7, 14, 21 дни эксперимента. Интенсивность процессов ПОЛ оценивали, исследуя содержание гидроперекисей липидов, диеновых конъюгатов, малонового диальдегида и основных компонентов АОC (церулоплазмина, витамина E, каталазы и глюкозо-6-фосфатдегидрогеназы) в плазме крови крыс по методикам, изложенным в ранее опубликованных нами работах $[2,3,10$, 11]. Статистическую обработку результатов проводили с использованием критерия Стъюдента (t) с помощью программы Statistica v.6.0. Резуль- таты считали достоверными при р<0,05.

\section{Результаты и их обсуждение}

В результате проведенных исследований было установлено, что воздействие низких температур на крыс сопровождается активацией ПОЛ и накоплением продуктов пероксидации в крови охлаждаемых животных (табл. 1). Доказано, что активация ПОЛ при холодовом воздействии на крыс развивается на фоне напряжения и истощения АОС крови, характерные изменения которой включают снижение активности каталазы и глюкозо-6-фосфатдегидрогеназы, а также уменьшение содержания витамина $\mathrm{E}$ и церулоплазмина (табл. 2).

Прооксидантное действие холода на организм нуждается в усиленном энергетическом обеспечении, потенциал которого связан с активацией гипофиз-адреналовой системы. При возрастании нагрузки на любую систему организма увеличивается окисление янтарной кислоты и мощность системы энергопродукции, использующей янтарную кислоту, которая в сотни раз превосходит все другие системы энергообразования организма. Цитофлавин увеличивает превращение янтарной кислоты в организме, необходимое для обеспечения жизнедеятельности в экстремальных условиях, способствует увеличению выхода тепла при мышечном сокращении, позволяющего при сниженном уровне терморегуляторного тонуса увеличивать теплопродукцию на холоде $[1,8]$, стабилизирует процессы липопероксидации в условиях холодовой экспериментальной модели, что подтверждается достоверным снижением содержания продуктов ПОЛ: гидроперекисей липидов на 12\%, 21\%, 20\% на 7, 14 и 21 дни эксперимента соответственно, диеновых конъюгатов на 19\%, 23\% и 17\%, малонового диальдегида на 28\%, 33\% и 20\% (табл. 1).

Уменьшение степени накопления продуктов радикального характера на фоне применения цитофлавина связано, по-видимому, с наличием в составе препарата не только янтарной кислоты, антиоксидантное действие которой доказано в экспериментальных и клинических исследованиях $[8,12,15]$, но и обусловлено входящим в комплекс рибофлавином, антиокси-

Резюме Представлены результаты исследований, направленных на решение важнейшей проблемы - защиты организма от стресса и экологически неблагоприятных факторов окружающей среды. В экспериментальных условиях исследована возможность коррекции свободнорадикального окисления липидов мембран организма крыс введением цитофлавина. Установлено, что ежедневное холодовое воздействие в течение трех часов способствует повышению содержания гидроперекисей липидов, диеновых конъюгатов, малонового диальдегида на фоне снижения активности основных компонентов антиоксидантной системы в крови экспериментальных животных. Введение крысам цитофлавина в условиях холодовой нагрузки способствует достоверному снижению в плазме крови гидроперекисей липидов на 13-21\%, диеновых конъюгатов - на 24-25\%, малонового диальдегида - на 20-33\% по сравнению с крысами контрольной группы. При анализе влияния цитофлавина на активность компонентов антиоксидантной системы было установлено, что содержание церулоплазмина и витамина Е в крови животных было достоверно выше аналогичного показателя у крыс контрольной группы на 10-33\%. Таким образом, использование цитофлавина в условиях длительного воздействия на организм экспериментальных животных холода приводит к стабилизации процессов пероксидации на фоне повышения активности основных компонентов антиоксидантной системы.

Ключевые слова: холодовая адаптация, цитофлавин, перекисное окисление липидов биологических мембран, продукты пероксидации (гидроперекиси липидов, диеновые конъюгаты, малоновый диальдегид), антиоксидантная система, крысы. 
Таблица 1. Содержание продуктов ПОЛ в крови крыс при холодовом воздействии и введении цитофлавина

\begin{tabular}{|c|c|c|c|c|}
\hline 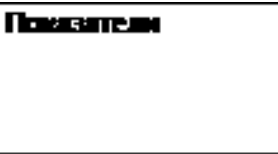 & $\begin{array}{l}\text { An } \\
\text { कास }\end{array}$ & $\begin{array}{l}\text { Грy-18 } 1 \\
\text { mitz:maga } \\
\mathbf{n}=\mathbf{3 0}\end{array}$ & 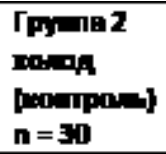 & 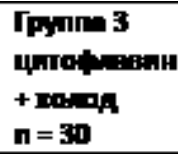 \\
\hline \multirow{3}{*}{$\begin{array}{l}\text { Диеновые } \\
\text { конъюгаты, } \\
\text { нмоль/мл }\end{array}$} & 7 день & $34,4 \pm 3,9$ & $45,1 \pm 2,2$ & $36,8 \pm 1,0^{*}$ \\
\hline & 14 день & $35,4 \pm 3,0$ & $47,7 \pm 2,5$ & $36,9 \pm 1,1$ \\
\hline & 21 день & $31,2 \pm 2,6$ & $44,0 \pm 1,8$ & $36,6 \pm 0,7$ \\
\hline \multirow{3}{*}{ 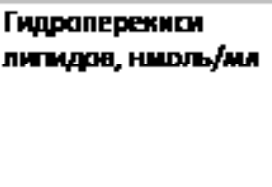 } & 7 день & $26, D \pm 1,8$ & $33,2 \pm 1,1$ & $29,3 \pm 1,1^{*}$ \\
\hline & 14 день & $25,0 \pm 2,7$ & $35,2 \pm 1,2$ & $27,9 \pm 1,1^{\prime \prime}$ \\
\hline & 21 Aень & $28,6 \pm 1,5$ & $35,6 \pm 1,1$ & $23,4 \pm 1,0$ \\
\hline \multirow{3}{*}{$\begin{array}{l}\text { Малоновый } \\
\text { диальдегид, } \\
\text { нмоль/мл }\end{array}$} & 7 день & $3,8 \pm 0,1$ & $5,8 \pm 0,2$ & $4,2 \pm 0,1$ \\
\hline & 14 день & $3,8 \pm 0,2$ & $6,6 \pm 0,4$ & $4,4 \pm B, 73$ \\
\hline & 21 день & $4,4 \pm 0,3$ & $5,6 \pm 0,4$ & $4,5 \pm 0,2$ \\
\hline
\end{tabular}

Примечание: * - достоверность различия показателей по сравнению с группой интактных животных (р<0,05); ** - достоверность различия показателей по сравнению с контрольной группой животных, к которым применяли только воздействие холода $(p<0,05)$.

дантные свойства которого, вероятно, реализуются путем его восстановления в семихинонную форму свободными радикалами, в дальнейшем семихинонные радикалы рибофлавина диспропорционируют с образованием молекулы рибофлавина. Данные факты были подтверждены нами результатами исследования активности основных компонентов АОС (табл. 2), которые отразили повышение уровня церулоплазмина на фоне введения цитофлавина на 15\%, 19\%, 20\% на 7, 14 и 21 дни эксперимента соответственно $(p<0,05)$, что, на наш взгляд, связано с восстановлением янтарной кислоты в дыхательной цепи митохондрий, возрастанием антиоксидантной активности глутатиона и синтеза церулоплазмина путём введения экзогенного сукцинат-содержащего препарата. Содержание витамина Е при использовании цитофлавина в эксперименте достоверно увеличилось на $14 \%$ к концу первой недели исследований, на $20 \%$ - к концу второй и на
$15 \%$ - к концу третьей $(p<0,05)$. В свою очередь, исследование активности ферментов антиоксидантной защиты позволило констатировать незначительное повышение уровня глюкозо-6-фосфатдегидрогеназы (в среднем на 7\%) и каталазы (на 8 - 18\%), однако различия по данным показателям были недостоверными.

Таким образом, содержание основных компонентов АОС (церулоплазмина и витамина Е) в крови экспериментальных животных, получавших цитофлавин, достоверно указывает на антиоксидантную активность препарата, который стабилизирует процессы ПОЛ в условиях холодового стресса и облегчает адаптацию организма к действию низких температур, на наш взгляд, за счет взаимодополняющего действия янтарной кислоты, рибоксина, рибофлавина и никотинамида в его составе. Все компоненты цитофлавина являются естественными метаболитами организма, утилизируются клеточными структурами,

\title{
COLD ADAPTATION OF THE WARM-BLOODED ORGANISM AND ITS CORRECTION BY CYTOFLAVIN
}

\section{V.A. Dorovskikh, N.V. Simonova, R.A. Anokhina, M.A. Shtarberg, E.Yu. Lemesh}

FSBEI HE the Amur state medical Academy of the Ministry of Public Health of Russia, Blagoveshchensk

\begin{abstract}
The results of investigations aimed at the solution of the important problem - protection of the organism from stress and ecologically unfavourable factors of the environment are presented. In experimental conditions the possibility to correct free radical lipid oxidation of rats' organism membranes was studied with the introduction of the cytoflavin. It is established that daily cold influence during three hours contributes to the increase of lipid hydroperoxides level, of diene conjugate, of malonic dialdehyde against the decrease of antioxidant system activity in the blood of animals under experiment. The introduction of the cytoflavin to rats in the conditions of cold influence contributes to the reliable decrease of lipid hydroperoxides by $13-21 \%$, of diene conjugates - by $24-25 \%$, malonic dialdehyde - by $20-33 \%$ in the blood in comparison with the rats of the control group. While analyzing the effect of the cytoflavin on the activity of the components of antioxidant system it was shown that the level of ceruloplasmin and vitamin $E$ in the blood of animals was reliably higher than analogous indicator in rats of the control group by $10-33 \%$. So, the application of the cytoflavin in the conditions of long influence of cold on the organism of animals under experiment leads to the stabilization of the processes of peroxidation against the increase of antioxidant system activity.
\end{abstract}

Key words: cold adaptation, cytoflavin, biological membranes lipid peroxidation, products of peroxidation (lipid hydroperoxides, diene conjugates, malonic dialdehyde), antioxidant system, rats. 
Таблица 2. Содержание компонентов АОС в крови крыс при холодовом воздействии и введении цитофлавина.

\begin{tabular}{|c|c|c|c|c|}
\hline 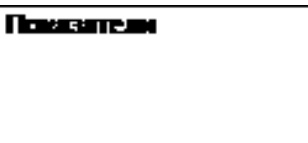 & $\begin{array}{l}\text { Aнu } \\
\text { काषाए }\end{array}$ & 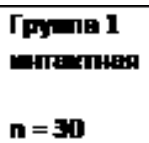 & 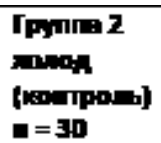 & 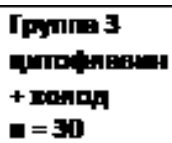 \\
\hline \multirow{3}{*}{$\begin{array}{l}\text { Церулоплазмин, } \\
\text { мкг/мл }\end{array}$} & 7 день & $30,0 \pm 1,9$ & $21,5 \pm 0,7$ & $25,4 \pm 0,9 *$ \\
\hline & 14 дЕК & $28, B \pm 1,4$ & $20,5 \pm 0,9$ & $25,4 \pm 1,4$ \\
\hline & 21 день & $26,8 \pm 1,4$ & $21,0 \pm 0,6$ & $26,1 \pm 1,7$ \\
\hline \multirow[t]{3}{*}{ Вмтамин E, шкг/мn } & 7 ден & $48,7 \pm 3,6$ & $37,3 \pm 1,9$ & $43,5 \pm 1,7$ \\
\hline & 14 день & $47,5 \pm 2,2$ & $34,0 \pm 1,6$ & $42,2 \pm 1,0$ \\
\hline & 21 ден & $45, B \pm 2,0$ & $3 B, 0 \pm 1,8$ & $44,4 \pm 1,0$ \\
\hline \multirow{3}{*}{$\begin{array}{l}\text { Глюкозо-6- } \\
\text { фосфатдегидро- } \\
\text { геназа, } \\
\text { НАДФН } \pi^{-1} c^{-1} \quad \text { мкмоль }\end{array}$} & 7 день & $6,9 \pm 0,2$ & $5,6 \pm 0,2$ & $6,0 \pm 0,3$ \\
\hline & 14 деF & $6,8 \pm 0,2$ & $5,9 \pm 0,2$ & $6,3 \pm 0,1$ \\
\hline & 21 день & $6,7 \pm 0,3$ & $5,6 \pm 0,2$ & $6,0 \pm 0,2$ \\
\hline \multirow{3}{*}{$\begin{array}{l}\text { Karanga, } \\
\mathrm{H}_{2} \mathrm{O}_{2} \mathrm{r}^{-1} \mathrm{C}^{-1}\end{array}$} & 7 ден & $93, D \pm 2,7$ & $\pi B, 6 \pm 5,1^{*}$ & $\mathrm{BS}, \mathrm{D} \pm 3, \mathrm{~B}$ \\
\hline & 14 день & $95,2 \pm 3,2$ & $72,8 \pm 5,9$ & $88,8 \pm 5,0$ \\
\hline & 21 декі & $97,0 \pm 3,5$ & $71,0 \pm 4,2$ & $B 1,4 \pm 4,2$ \\
\hline
\end{tabular}

Примечание: * - достоверность различия показателей по сравнению с группой интактных животных (р<0,05); ** - достоверность различия показателей по сравнению с контрольной группой животных, к которым применяли только воздействие холода $(p<0,05)$.

участвуют в окислительно-восстановительных реакциях, способствуют снижению интенсивности ПОЛ, активации системы антиоксидантной защиты, что приводит к нормализации обменных процессов в организме. Кроме того, прослеживается прямая зависимость между антиокислительным эффектом цитофлавина и длительностью его применения: препарат начинает действовать уже на 7 день, максимальная эффективность наблюдается к концу второй недели эксперимента.

В целом впервые доказана эффективность коррекции холодового стресса в эксперименте введением препарата цитофлавин, что позволяет рекомендовать данное лекарственное средство к применению в комплексной терапии заболеваний, протекающих на фоне липидной пероксидации.

\section{Выводы}

1. Экспериментально подтверждена возможность коррекции холодового стресса введением сукцинатсодержащего препарата цитофлавин.

2. Внутрибрюшинное введение цитофлавина лабораторным животным (крысам) в дозе 100 мг/кг снижает интенсивность процессов ПОЛ биомембран, индуцированных длительным холодовым воздействием, восстанавливая стационарный уровень продуктов пероксидации на фоне достоверного увеличения активности основных компонентов АОС (церулоплазмина и витамина E).

3. Результаты исследования дают основание рекомендовать цитофлавин в качестве антиоксиданта, а также регулятора адаптационных реакций организма при воздействии низких температур.

\section{Литература}

1. Доровских В.А., Симонова Н.В., Коршунова Н.В. Адаптогены в регуляции холодового стресса. Saabrucken, 2013. 266 c.

2. Доровских В.А., Симонова Н.В., Симонова И.В., Штарберг М.А. Применение фитопрепаратов для коррекции процессов перекисного окисления липидов биомембран, индуцированных ультрафиолетовым облучением // Дальневосточный медицинский журнал. 2011. №1. С. 77-79.

3. Доровских В.А., Симонова Н.В., Тонконогова М.С., Пнюхтин О.П., Симонова Н.П. Сравнительная оценка фитоадаптогенов при окислительном стрессе // Бюллетень физиологии и патологии дыхания. 2015. Вып.55. С. 95-100.

4. Костюк В.А., Потапович А.И. Биорадикалы и биоантиоксиданты. Минск, 2004. 192 с.

5. Ландышев Ю.С., Доровских В.А., Целуйко С.С., Лазуткина Е.Л., Ткачева С.И., Чапленко Т.Н. Бронхиальная астма. Благовещенск: АГМА, 2010. 136 c.

6. Ландышев Ю.С., Доровских В.А., Чапленко Т.Н. Лекарственная аллергия. СПб.: Нордмедиздат, 2010. 192 c.

7. Новиков В.Е., Левченкова О.С. Новые направления поиска лекарственных средств с антигипоксической активностью и мишени для их действия // Экспериментальная и клиническая фармакология. 2013. Т. 76, №5. С. 37-47.

8. Оковитый С.В., Шуленин С.Н., Смирнов А.В. Клиническая фармакология антигипоксантов и антиоксидантов. СПб.: ФАРМиндекс, 2005. 72 с.

9. Симонова И.В., Доровских В.А., Симонова Н.В., Штарберг М.А. Неспецифическая профилактика острых респираторных заболеваний у детей ясельного возраста // Дальневосточный медицинский журнал. 2009. №3. С. $56-58$. 
10. Симонова Н.В. Настои лекарственных растений и окислительный стресс в условиях ультрафиолетового облучения // Вестник Саратовского госагроуниверситета им. Н.И. Вавилова. 2011. № 8. С. 23-26.

11. Симонова Н.В. Фитопрепараты в коррекции процессов перекисного окисления липидов биомембран, индуцированных ультрафиолетовым облучением: автореф. дис. ... д-ра биол. наук. Благовещенск, 2012. 46 с.

12. Швец О.М. Теоретическое и экспериментальное обоснование применения янтарной кислоты для потенцирования биологической активности иммуномодуляторов и их клиническая эффективность: автореф. дис. ... д-ра биол. наук. Курск, 2015. 45 с.

13. Ярыгина Е.Г., Прокопьева В.Д., Бохан Н.А. Окислительный стресс и его коррекция карнозином // Успехи современного естествознания. 2015. № 4. С.106-113.

14. Aldini G., Yeum Kyung-Jim, Niki E., Russel R. Biomarkers for antioxidant defense and oxidative damage. Medical, 2011. 380 p.

15. Niizuma K., Endo H., Chan P. Oxidative stress and mitochondrial dysfunction as determinants of ischemic neuronal death and survival // J. Neurochem. 2009. Vol. 109. P. 133-138.

16. Pratt D.A., Tallman K.A., Porter N.A. Free radical oxidation of polyunsaturated lipids: New mechanistic insights and the development of peroxyl radical clocks // Acc. Chem. Res. 2011. Vol. 44. №6. P. 458467. Статья поступила в редакцию 02.02.2019

\section{Координаты для связи}

Доровских Владимир Анатольевич, заслуженный деятель науки РФ, д. М. Н., профессор кафедры госпитальной терапии с курсом фармакологии ФГБОУ ВО Амурская ГМА Минздрава России.

Симонова Наталья Владимировна, д. б. н., доцент кафедры госпитальной терапии с курсом фармакологии ФГБОУ ВО Амурская ГМА Минздрава России. E-mail: simonova.agma@yandex.ru

Анохина Раиса Афанасьевна, к. м. н., доцент кафедры госпитальной терапии с курсом фармакологии ФГБОУ ВО Амурская ГМА Минздрава России.

Штарберг Михаил Анатольевич, к. М. н., старший научный сотрудник ЦНИЛ ФГБОУ ВО Амурская ГМА Минздрава России.

Лемеш Елена Юрьевна, ассистент кафедры химии ФГБОУ ВО Амурская ГМА Минздрава России.

Почтовый адрес ФГБОУ ВО Амурская ГМА Минздрава России: 675000, Амурская область, г. Благовещенск, ул. Горького, $95 . \quad$ E-mail: AmurSMA@AmurSMA.su, science.dep@AmurSMA. su

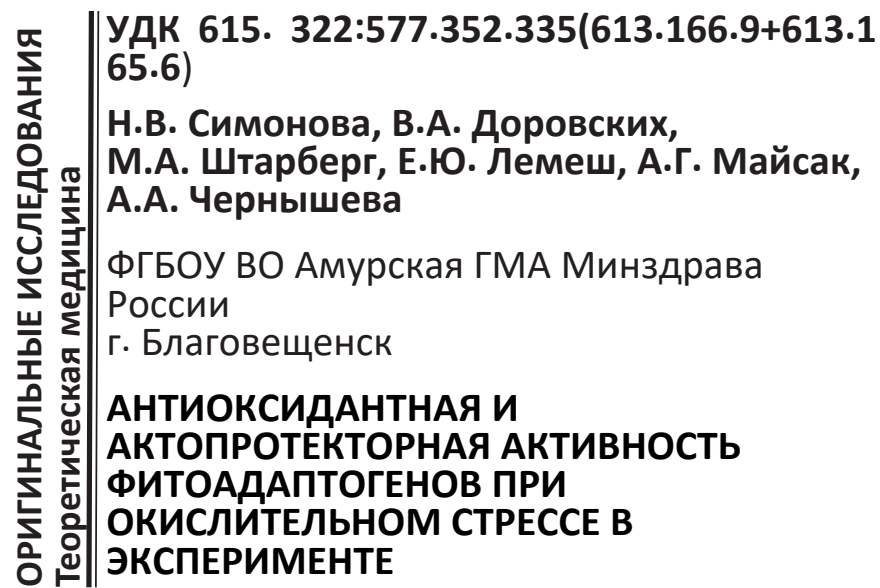

\section{Введение}

Повышение резистентности организма к действию стресс-факторов является актуальной задачей современной медицинской науки $[1,6,8$, 15]. В решении указанной проблемы большое значение принадлежит расширению доказательной базы эффективности адаптогенных средств растительного происхождения $[2,9]$. Преимущества средств природного происхождения перед синтетическими состоят в том, что они представляют собой комплексы биологически активных веществ, близких по своей природе эндогенным биорегуляторным соединениям, благодаря чему оказывают адекватное корригирующее действие на функциональное состояние организма на разных уровнях его биологической организации; обладают широким спектром активности и поливалентностью лечебного действия; характеризуются постепенным нарастанием эффекта, низкой токсичностью и отсутствием побочных реакций при длительном применении $[4,5,7,12]$.

На протяжении нескольких десятилетий кафедра фармакологии Амурской ГМА занималась изучением фармакологических эффектов адаптогенов, среди которых наиболее изученным амурскими исследователями является элеутерококк. Была доказана антиоксидантная, антигипоксантная, актопротекторная активность этого адаптогена в различных модельных системах (гипо-, гипертермия, ультрафиолетовое облучение). В настоящее время на кафедре проведены исследования, посвященные изучению

Резюме Современные условия окружающей среды резко повысили уровень радикалобразующих процессов в организме. Действие прооксидантных факторов индуцирует развитие критического состояния, которое сопровождается истощением энергетических и других резервов, снижением тканевого метаболизма, формированием пролиферативно-дистрофических расстройств во всех органах. В экспериментальных условиях исследована возможность коррекции свободнорадикального окисления липидов мембран организма крыс пероральным введением фитоадаптогенов, содержащих комплекс природных антиоксидантов.

Ключевые слова: фитоадаптогены, окислительный стресс, ультрафиолетовое облучение, перекисное окисление липидов биологических мембран, продукты пероксидации (гидроперекиси липидов, диеновые конъюгаты, малоновый диальдегид), антиоксидантная система, крысы. 